\title{
MICRORGANISMOS MESOFÍLICOS EM LEITE UHT
}

\author{
Mesophilic microorganisms in UHT milk
}

Delane Ribas da Rosa ${ }^{1}$, Eduardo Sirichuk de Souza ${ }^{l}$, Julia Arantes Galvão ${ }^{\text {I* }}$

\section{RESUMO}

O leite tratado via ultra alta temperatura (UAT) - Ultra High Temperature - UHT está presente na maioria das dietas nacionais e assume papel fundamental na nutrição humana. Os microrganismos mesófilos destacam-se como principais indicadores de qualidade do produto. Assim, o objetivo deste trabalho foi detectar, quantificar e avaliar a morfologia de Gram das bactérias mesófilas isoladas de três diferentes marcas de leite UHT submetidos ou não à incubação. Foram obtidas em supermercados da região de Curitiba, PR, 90 amostras de leite UHT (A, B e C). Metade das amostras foi submetida a incubação $\left(36^{\circ} \mathrm{C} / 7\right.$ dias $)$ previamente às análises e a outra metade foi avaliada em até $2 \mathrm{~h}$ após a aquisição quanto à Contagem Padrão em Placas (CPP), coloração de Gram e teste da lactofermentação. 30\% das amostras analisadas continham mais que $100 \mathrm{UFC} / \mathrm{mL}$ de aeróbios mesófilos, sendo $20 \%$ e $29 \%$ das amostras incubadas ou não, respectivamente. A marca A apresentou as maiores contagens, seguida pelas marcas B e C. Os resultados após incubação também revelam maiores contagens nas amostras da marca A. Os resultados de coloração de Gram revelaram a predominância de cocos Gram-positivos em todas as amostras, incubadas ou não. No teste de lactofermentação, verificou-se coagulação após 48 h e 96 h de incubação em, pelo menos, uma amostra sem incubação prévia e nas amostras com incubação por sete dias nas amostras das marcas A e B (lotes 1 e 3). Logo, identificou-se a possibilidade de haver amostras e marcas de leite UHT disponíveis no mercado que extrapolam os limites estabelecidos pela legislação em relação à contagem de microrganismos mesófilos.

Palavras-chave: coagulação; lactofermentação; leite incubado.

1 Universidade Federal do Paraná, Setor de Ciências Agrárias, Rua dos Funcionários, 1540, Juvevê, 80035-050, Curitiba, PR, Brasil.E-mail: julia.galvao@ufpr.br

* Autor para correspondência

Recebido / Received: 24/08/2020

Aprovado / Approved: 16/10/2020 


\begin{abstract}
Milk treated by Ultra High Temperature - UHT is present in most national diets and takes a fundamental role in human nutrition. Mesophilic microorganisms stand out as the main product quality indicators. Thus, the objective of this paper was to detect, quantify and evaluate the Gram morphology of mesophilic bacteria isolated from three different brands of UHT milks submitted or not to incubation. 90 samples of UHT milk (A, B, and C) were obtained from supermarkets in the region of Curitiba, PR. Half of the samples were subjected to incubation $\left(36^{\circ} \mathrm{C} / 7\right.$ days $)$ before analysis and the other half was evaluated within 2 hours after acquisition for Standard Plate Count (SPC), Gram staining, and lactofermentation test. 30\% of the analyzed samples contained more than $100 \mathrm{CFU} / \mathrm{mL}$ of mesophilic aerobes, with $20 \%$ and $29 \%$ of the samples incubated or not, respectively. The A mark had the highest counts, followed by the $\mathrm{B}$ and $\mathrm{C}$ marks. The results after incubation also revealed higher counts in the A mark samples. The Gram stain results revealed the predominance of Gram-positive cocci in all samples, incubated or not. In the lactofermentation test, coagulation was observed after $48 \mathrm{~h}$ and $96 \mathrm{~h}$ of incubation in at least one sample without previous incubation and in samples with incubation for seven days of brands A and B (batches 1 and 3). Therefore, it was identified the possibility of having samples and brands of UHT milk available on the market that go beyond the limits established by legislation concerning the counting of mesophilic microorganisms.
\end{abstract}

Keywords: coagulation; lactofermentation; incubated milk.

\section{INTRODUÇÃO}

O processo UAT (Ultra Alta Temperatura, em inglês Ultra High Temperature, UHT) consiste no aquecimento do leite, previamente homogeneizado, à temperatura de 130 a $150{ }^{\circ} \mathrm{C}$ durante 2 a 4 segundos, sob fluxo contínuo, com o rápido resfriamento a $32{ }^{\circ} \mathrm{C}$. O envase é realizado sob condições assépticas em embalagens estéreis e hermeticamente fechadas (BRASIL, 1996).

O leite UHT está presente em $87 \%$ das moradias brasileiras, representando $76 \%$ do leite fluido e $47 \%$ do total de leites consumidos no Brasil (CAMARA; WESCHENFELDER, 2014). Por outro lado, uma pesquisa realizada por Ornellas et al. (2018) revelaram que apesar da existência de processos de beneficiamento que tornam o leite livre de microrganismos patogênicos, ainda é observada a preferência de alguns grupos de consumidores pelo leite sem tratamento térmico, o que é um risco a saúde pública.

As características físico-químicas e condições de higiene na ordenha influenciam diretamente a qualidade do leite, até mesmo o submetido ao processo UHT, pois as bactérias da matéria-prima são eliminadas, porém deixam enzimas que degradam alguns compostos de interesse econômico, como a lactose (TRONCO, 2010).

O leite e demais produtos submetidos ao tratamento UHT não devem conter nenhum tipo de microrganismos patogênicos ou alteradores das características físicas, químicas e sensoriais em condições adequadas de armazenamento (BRASIL, 1996). No entanto, permite-se que após sete dias de incubação de 35 a $37^{\circ} \mathrm{C}$ tenha-se a contagem de $100 \mathrm{UFC} / \mathrm{mL}$ (BRASIL, 1997). Isso devido 
ao fato de que este processo térmico é capaz de eliminar todas as formas vegetativas, restando as formas esporuladas altamente resistentes ao calor (Highly Heat Resistant Spores - HHRS).

Os aditivos são substâncias naturais ou artificiais adicionadas aos alimentos que desempenham diversas funções. No leite UHT os citratos e fosfatos funcionam como quelantes de cálcio e estabilizadores de micelas (WANG et al., 2016), com isso é possível minimizar a ocorrência de sedimentação, e gelificação, assim como promover a estabilidade das proteínas (CHEN et al., 2012). No entanto, a qualidade microbiológica do leite é fundamental para que o leite submetido a tratamento térmico não apresente sedimentações ou gelificação (NEWSTEAD et al., 2006).

Para realizar a avaliação qualitativa do leite são utilizados microrganismos indicadores. Os comumente pesquisados são os microrganismos aeróbios ou facultativos, dentre os quais estão os mesófilos, termófilos, psicrotróficos, e os coliformes (REZENDE et al., 2000). No entanto, Maieski (2011) destaca como principais microrganismos indicadores de qualidade do leite: os aeróbios mesófilos e coliformes.

A contaminação do leite cru pode elevar a representatividade das bactérias psicrotróficas em mais de 75\% da microbiota, já quando são aplicados adequados cuidados na ordenha, a contaminação é reduzida a $10 \%$ da microbiota do leite cru (SERRA, 2004). Isso, consequentemente, altera a quantidade de proteases e lipases deteriorantes (JAY, 2000).

Assim, considerando o alto consumo de leite UHT pela população brasileira (CARVALHO et al., 2020) e a preocupação com a segurança e qualidade dos alimentos, o presente trabalho teve como objetivo detectar, quantificar e caracterizar morfologicamente as bactérias aeróbias mesófilas de leites UHT do tipo integral de três diferentes marcas disponíveis no comércio varejista de Curitiba e região, Paraná.

\section{MATERIAIS E MÉTODOS}

Foram avaliadas 90 amostras de leite UHT de três diferentes marcas, denominadas como A, B e C, separadas em três lotes de cada marca, obtidas em supermercados da região de Curitiba, PR. De acordo com as informações da embalagem, os leites avaliados apresentavam a seguinte composição: A - leite integral; B - leite fluido integral, estabilizante monofosfato de sódio, difosfato de sódio, trifosfato de sódio e citrato de sódio; C leite integral, estabilizantes citrato de sódio, monofosfato de sódio, difosfato de sódio e trifosfato de sódio.

De cada marca foram adquiridas 10 amostras quinzenalmente, sendo cinco delas analisadas em até 2 horas no dia da aquisição e outras cinco após incubação de 36 a $37^{\circ} \mathrm{C}$ por 7 dias. A avaliação das amostras foi realizada conforme a recomendação do Regulamento Técnico de Identidade e Qualidade (RTIQ), mediado pela Portaria $\mathrm{n}^{\circ} 146$ do Ministério da Agricultura e Pecuária (BRASIL, 1996). Todas as análises foram realizadas dentro do prazo de validade especificado em cada embalagem.

Foi realizada a assepsia externa das caixas com a lavagem em água e sabão, com auxílio de uma esponja descartável, enxágue, secagem e aplicação de álcool $70 \%$ v/v na região de abertura.

Para a realização da Contagem Padrão em Placa (CPP) procedeu-se a diluição em solução salina $0,85 \% \mathrm{NaCl}$ e posterior semeadura em superfície em ágar padrão de contagem (BRASIL, 2003). Após a semeadura, as placas foram incubadas por 48 horas de 36 a $37^{\circ} \mathrm{C}$. Em seguida, foi realizada a contagem em Unidades Formadoras de Colônia (UFC) e triagem (de modo aleatório, considerando a boa condição de isolamento) de duas colônias de cada amostra para a coloração de Gram e identificação morfológica.

Adicionalmente foi realizado teste da 
lactofermentação utilizando $10 \mathrm{~mL}$ de cada amostra adicionados em tubos de ensaio estéreis com tampa de rosca e incubados de 36 a $37^{\circ} \mathrm{C}$ com leituras após 24 horas, 48 horas, 72 horas e 96 horas (PINTO et al., 2006).

As análises foram processadas no Laboratório de Controle de Qualidade e Segurança de Alimentos (LACQSA) da UFPR.

\section{RESULTADOS E DISCUSSÃO}

Das 90 amostras analisadas, nenhuma apresentou "estufamento" nas embalagens ou coagulação visível no momento de abertura das caixas de leite, mesmo após incubação de 36 a $37^{\circ} \mathrm{C}$ por sete dias.

Dado que o binômio temperatura e tempo do processo UHT não é capaz de proporcionar ao produto a esterilidade total (LUZ et al., 2018), a regulamentação vigente estipula o limite de $100 \mathrm{UFC} / \mathrm{mL}$ para contagens de aeróbios mesófilos (BRASIL, 1997). Das 90 amostras analisadas, 30\% apresentaram contagens acima de $100 \mathrm{UFC} / \mathrm{mL}$, sendo $29 \%$ das amostras não incubadas e $20 \%$ das amostras incubadas (Tabela 1).

Em comparação entre as marcas sem incubação, a marca A é a que apresentou maiores contagens, seguido pela marca $\mathrm{B}$ e C. Já os resultados após incubação a $36^{\circ} \mathrm{C}$ por sete dias revelam maiores contagens nas amostras da marca A, apesar de amostras da marca B apresentarem a mesma quantidade de contagens acima do estabelecido pela legislação nacional (BRASIL, 1997), porém com menores contagens (Tabela 2).

Relatos de altas contagens bacterianas em leite UHT são apresentados em alguns estudos como o de Pereira et al. (2013) que detectou a presença e contagens acima de $100 \mathrm{UFC} / \mathrm{mL}$ em $38 \%$ das amostras e em $24 \%$ das amostras da pesquisa de Bersot et al. (2010) também estavam acima do recomendado. Westhoff (1981), associa estas contaminações a falhas no sistema de envase e a higiene inadequada dos equipamentos que realizam os processos térmicos.

$\mathrm{O}$ leite da marca $\mathrm{C}$ apresentou contagem em quatro das trinta amostras analisadas com e sem incubação, todas acima do limite permitido (Tabela 2). O leite que apresenta boas condições microbiológicas antes do processamento em virtude de uma série de fatores que inclui a saúde dos animais, dos trabalhadores da ordenha, realização de

Tabela 1 - Número de amostras de leite UHT distribuídas nas faixas de contagens de microrganismos aeróbios mesófilos, avaliados sem incubação e após incubação de 36 a $37{ }^{\circ} \mathrm{C}$ por sete dias, por marcas (A, B e C)

\begin{tabular}{|c|c|c|c|c|c|c|c|}
\hline \multirow{2}{*}{$\begin{array}{c}\text { Faixa de contagem } \\
\text { bacteriana }(\mathrm{UFC} / \mathrm{mL})\end{array}$} & \multicolumn{3}{|c|}{ Amostras não incubadas } & \multicolumn{3}{|c|}{ Amostras incubadas } & \multirow{2}{*}{ Total } \\
\hline & $\mathbf{A}$ & B & $\mathrm{C}$ & $\mathbf{A}$ & B & $\mathrm{C}$ & \\
\hline$<10$ & 6 & 7 & 12 & 8 & 6 & 14 & 53 \\
\hline 11-100 & 1 & 2 & 0 & 1 & 3 & 0 & 7 \\
\hline $101-200$ & 0 & $2 *$ & 0 & 0 & $1 *$ & 0 & $3 *$ \\
\hline 201-300 & $1 *$ & $1 *$ & 0 & 0 & 0 & 0 & $2 *$ \\
\hline$>301$ & $7 *$ & $3 *$ & $3 *$ & $6^{*}$ & $5^{*}$ & $1 *$ & $25^{*}$ \\
\hline Total & 15 & 15 & 15 & 15 & 15 & 15 & 90 \\
\hline
\end{tabular}

Legenda: *Número de amostras que extrapolaram o limite máximo de 100 UFC/mL (BRASIL, 1997). 
boas práticas de ordenha apresentará melhor condição microbiológica também após o processamento (TRONCO, 2010).

Pesquisando cinco diferentes marcas de leites UHT na Paraíba, Silva et al. (2019) constataram contagens de coliformes menor que $0,3 \mathrm{NMP} / \mathrm{mL}$, assim como ausência de Salmonela sp. e Escherichia coli. Os autores relacionam este resultado com o adequado processamento térmico e ausência de contaminação posterior o que são comprovadas pela ausência destes tipos de bactérias.

Para monitorar o grau de contaminação microbiana de uma amostra em quantidades ou unidade formadora de colônia (UFC), Brito; Brito (2004) apontam a Contagem Bacteriana Total (CBT) como fundamental para retratar os cuidados desde a ordenha até o momento da estocagem de determinado laticínio. Esta análise depende da carga microbiana inicial e da capacidade de multiplicação do microrganismo (MAIESKI, 2011).

A bactéria esporulada mais popular mundialmente isolada de leites UHT é o Bacillus sporothermodurans - BSP (ZACARCHENCO et al., 2000). Os resultados obtidos a partir do isolamento do bacilo de amostras de leites UHT produzidos nos estados de São Paulo e Paraná apresentaram contagens em torno de $10^{5} \mathrm{UFC} / \mathrm{mL}$ e não se constatou alterações sensoriais. A posterior multiplicação dessas bactérias promove a perda de qualidade do leite e degradação de seus componentes por microrganismos ou enzimas microbianas, podendo ter implicações negativas em textura, sabor e aroma do leite (HAYES; BOOR, 2001). Mais recentemente, Tabit (2018) confirma o que os autores anteriores afirmaram, pois observou menores taxas proteolíticas de BSP e alterações sensoriais após a fase de crescimento exponencial deste bacilo em seu experimento com leites UHT com validades atingidas.

$\mathrm{Na}$ coloração de Gram observamos predominância de cocos Gram-positivos nas amostras não incubadas e incubadas, o que corrobora com o estudo de Bersot et al. (2010), que de 150 amostras de três diferentes marcas identificou cocos Gram-positivos na maioria delas. Segundo Jay (2005), dentre as bactérias Gram-positivas, cocos são mais resistentes ao calor do que os bacilos, sendo Bacillus com representação de $38,4 \%$ das bactérias encontradas na pesquisa de Luz et al. (2018).

Nas amostras não incubadas foram identificadas bactérias do tipo cocos Gram positivas e negativas nas marcas A, B e C. As amostras incubadas das três marcas apresentaram morfologias de cocos Gram positivos (Tabela 3)

Tabela 2 - Contagens máximas, mínimas e média de aeróbios mesófilos em UFC/mL de amostras de leite UHT avaliados sem incubação e após incubação de 36 a $37{ }^{\circ} \mathrm{C}$ por sete dias, por marcas (A, B e C)

\begin{tabular}{ccccc}
\hline \multirow{2}{*}{ Marcas } & \multicolumn{2}{c}{ Amostras não incubadas } & \multicolumn{2}{c}{ Amostras incubadas } \\
\cline { 2 - 5 } & Máx-Mín & Média & Máx-Min & Média \\
\hline A & $16000-65$ & 11702 & $48100-10$ & 3601 \\
B & $9250-10$ & 1251 & $14850-10$ & 2474 \\
C & $18505-5450$ & 13364 & 400 & 27 \\
\hline
\end{tabular}


Nos testes de lactofermentação, evidenciou-se características alterações sensoriais. Apesar das observações a cada 24 horas, os três lotes de todas as marcas manifestaram coagulação após $48 \mathrm{~h}$ ou $96 \mathrm{~h}$ de incubação em, pelo menos, uma amostra sem incubação prévia. Com a incubação por sete dias, os lotes 1 e 3 das marcas A e B apresentaram pelo menos uma ocorrência de coagulação espalhadas nos quatro tempos de observação. Este maior tempo de coagulação está vinculado a baixa carga microbiana, devido processo UHT, e ao isolamento proporcionado pela embalagem. No entanto, ao longo do tempo de incubação foi observada a presença de algumas culturas viáveis constatada pela formação de coágulos consistente irregular com liberação de soro.

Podemos relacionar a ocorrência de coagulação com os resultados apresentados na coloração de Gram. Em algumas amostras houve a formação de gás. No entanto, no lote 2 das marcas A e B e todos os lotes da marca C submetidos a incubação prévia por 7 dias as amostras apresentaram contagens e não houve coagulação.

Diante desta constatação, podemos elencar alguns fatores que desencadeiam a sedimentação e gelificação como nos resultados de Malmgren et al. (2017) o qual, em seus estudos na Suécia, concluíram que a temperatura de armazenamento é um fator que está fortemente relacionado a sedimentação e a gelificação do leite após processamento UHT.

Segundo Dias (2011), a gelificação inicia-se a partir da hidrólise da caseína devido a ação da plasmina ou enzimas microbianas termoresistentes. Ainda, a mesma autora aponta a plasmina, enzima natural do leite, como responsável pela gelificação em leite UHT oriundo de leite cru de boa qualidade, já quando utiliza-se leite cru de baixa qualidade, este fenômeno pode ser associado a enzimas microbianas termorresistentes produzidas por bactérias psicrotróficas. A permanência destas enzimas nativas ou microbianas já havia sido observada por Burton (1988), sendo estas responsabilizadas por alterações de sabores após armazenamento.

Outros fatores como a natureza do processamento térmico, a atividade proteolítica durante o armazenamento, a composição e qualidade da matéria-prima, temperatura de armazenamento e a adição excessiva de aditivos como fosfato de sódio e citrato de sódio são significativos para iniciar a gelificação ou acelerar este processo (DATTA; DEETH, 2001).

Dias (2011) e Beloti (2015) relatam que citratos e fosfatos são utilizados em leite

Tabela 3 - Análise morfológica e coloração de Gram de colônias bacterianas mesofílicas isoladas em leites UHT de três marcas (A, B e C) por lote avaliado

\begin{tabular}{cccccccc}
\hline \multirow{2}{*}{ Marcas } & \multicolumn{3}{c}{ Amostras não incubadas } & \multicolumn{4}{c}{ Amostras incubadas } \\
\cline { 2 - 7 } & 1 & 2 & 3 & $\mathbf{1}$ & $\mathbf{2}$ & $\mathbf{3}$ \\
\hline A & $\mathrm{C}+$ & $\mathrm{C}+$ & $\begin{array}{c}\mathrm{CB}-/ \\
\mathrm{C}+/ \mathrm{B}-\end{array}$ & $\mathrm{C}+$ & $\mathrm{C}+$ & 0 \\
B & $\mathrm{C}-$ & $\mathrm{C}-/ \mathrm{C}+$ & $\mathrm{C}-/ \mathrm{B}-/ \mathrm{C}+$ & $\mathrm{C}+$ & $\mathrm{C}+$ & 0 \\
C & $\mathrm{C}-$ & $\mathrm{C}+$ & 0 & $\mathrm{C}+$ & 0 & 0 \\
\hline
\end{tabular}

Legenda: $\mathrm{C}+=$ Cocos positivo; $\mathrm{C}-=$ Cocos negativo; $\mathrm{B}+=$ Bacilo positivo; $\mathrm{B}-=$ Bacilo negativo; $0=$ sem crescimento bacteriano. 
UHT, combinados ou não, e atuam como estabilizantes de caseína e são adicionados antes do processo térmico em concentração não superior a determinada pelo MAPA.

Os aditivos como estabilizantes são utilizados na indústria de laticínios para prevenir a sedimentação e gelificação do leite submetido ao tratamento com altas temperaturas, evitando a aparência de coalhado e garantindo um determinado tempo de armazenamento (SANTOS; FONSECA, 2007; CHEN et al., 2012). O MAPA estipula um limite de $0,1 \mathrm{~g} / 100 \mathrm{~mL}$ ou $0,1 \%$ no leite UHT dentre estabilizantes como citrato de sódio, monofosfato de sódio, difosfato de sódio, trifosfato de sódio, usados separados ou em combinação (BRASIL, 1997).

A estabilidade térmica do leite antes do beneficiamento está diretamente relacionada à qualidade do leite cru, a qual é definida pela higiene na ordenha e temperatura de armazenamento (DIAS, 2011), sendo o uso de estabilizantes opcional.

As amostras de leite $\mathrm{C}$ que não coagularam na prova da lactofermentação e apresentaram as menores contagens bacterianas podem ter passado por algum processamento adicional que proporcionou tal condição, não ficando excluída aqui a possibilidade do uso de inibidores não autorizados. Essa é uma hipótese que fica aventada, já que testes para pesquisa de inibidores não foram realizados neste estudo.

\section{CONCLUSÃO}

De acordo com os resultados apresentados neste estudo concluímos que pode haver amostras disponíveis no comércio varejista que extrapolam as $100 \mathrm{UFC} / \mathrm{mL}$ de bactérias mesofílicas (limite estabelecido pela legislação nacional), não sendo este resultado exclusivo de uma das marcas avaliadas. Medidas de controle higiênico-sanitário devem ser readequadas pelas unidades produtivas e indústria para que o consumidor receba um produto de melhor qualidade.

\section{REFERÊNCIAS}

BELOTI, V. Leite: Obtenção, Inspeção, Qualidade. Londrina: Editora Planta, 2015. $420 \mathrm{p}$.

BERSOT, L. S. et al. Avaliação microbiológica e físico-química dos leites UHT produzidos no Estado do Paraná, Brasil. Semina Ciências Agrárias, v. 31, n. 3, p. 645-652, 2010. DOI: 10.5433/1679-0359.2010v31n3p645

BRASIL. Ministério da Agricultura, do Abastecimento e da Reforma Agrária. Portaria $\mathrm{n}^{\circ} 146$, de 7 de março de 1996. Aprova os Regulamentos Técnicos de Identidade e Qualidade dos Produtos Lácteos. Diário Oficial da República Federativa do Brasil: seção 1, Brasília, DF, n. 48, p. 3977, 11 mar. 1996.

BRASIL. Ministério da Agricultura e do Abastecimento. Portaria $n^{\circ} 370$, de 4 de setembro de 1997. Regulamento Técnico de Identidade e Qualidade do Leite UHT (UAT). Diário Oficial da República Federativa do Brasil: seção 1, Brasília, DF, n. 172, p. 19.700, 8 set. 1997.

BRASIL. Ministério da Agricultura, Pecuária e Abastecimento. Instrução Normativa $n^{\circ}$ 62 , de 26 de agosto de 2003. Oficializa os Métodos Analíticos Oficiais para Análises Microbiológicas para Controle de Produtos de Origem Animal e Água. Diário Oficial da União: seção 1, Brasília, DF, n. 181, p. 14, 18 set. 2003.

BRITO, M. A. V. P.; BRITO J. R. F. Qualidade do leite. In: CAMPOS, O. F.; MIRANDA, J. E. C. (ed.). Gado de Leite: O produtor pergunta, a Embrapa responde. 2. ed. 
Brasília: Embrapa Informação Tecnológica, 2004. p. 61-74.

BURTON, H. Ultra-high-temperature Processing of Milk and Milk Products. London: Elsevier Applied Science, 1988. $354 \mathrm{p}$.

CAMARA, F. A.; WESCHENFELDER, S. Leite UHT integral: Avaliação da rotulagem nutricional e dos padrões de identidade e qualidade. Revista do Instituto de Laticínios Cândido Tostes, v. 69, n. 4, p. 268-279, 2014. DOI: $10.14295 / 2238-6416 . v 69 i 4.331$

CARVAlHO, G. R. et al. Resumo das informações discutidas na reunião de conjuntura da equipe do Centro de Inteligência do Leite, realizada em 11 de agosto de 2020. Juiz de Fora: EMBRAPA Gado de Leite, 2020. Disponível em: https://www. cileite.com.br/nota_conjuntura_ago 2020 . Acesso em: 15 out. 2020.

CHEN, B. Y.; GRANDISON, A. S.; LEWIS, M. J. Comparison of heat stability of goat milk subjected to ultra-high temperature and in-container sterilization. Journal of Dairy Science, v. 95, n. 3, p. 1057-1063, 2012. DOI: $10.3168 /$ jds.2011-4367

DATTA, N.; DEETH, H. C. Age gelation of UHT milk - A review. Food and Bioproducts Processing, v. 79, n. 4, p. 197-210, 2001. DOI: $10.1205 / 096030801753252261$

DIAS, M. E. F. Efeito da adição de $\mathrm{CO}_{2}$ ao leite cru sobre as características do leite UHT armazenado a diferentes temperaturas. Orientadora: Mirna Lúcia Gigante. 2011. 68 f. Dissertação (Mestrado em Tecnologia de Alimentos) - Faculdade de Engenharia de Alimentos, Universidade Estadual de Campinas, Campinas, 2011.

HAYES, M. C.; BOOR, K. Raw milk and fluid milk products. In: MARTH, E. H.; STEELE, J.L. (ed.). Applied Dairy Microbiology. New York: Marcel Dekker, 2001. v. 2, p. 59-76.

JAY, J. M. Modern Food Microbiology. 6th ed. New York: Chapman and Hall, 2000. 701 p.

LUZ, C. F.; SCHAFHAUSER, L. M.; SOUZA, V. G. Avaliação microbiológica e físicoquímica de amostras de leite UHT. 2018. 21 f. Trabalho de Conclusão de Curso (Tecnologia em Alimentos) - Universidade Tecnológica Federal do Paraná, Ponta Grossa, 2018.

MAIESKI, L. M. Os principais microorganismos patogênicos que afetam a qualidade do leite. 2011. 35 f. Trabalho de Conclusão de Curso (Especialista em Produção, Tecnologia e Higiene de Alimentos de Origem Animal) - Faculdade de Veterinária, Universidade Federal do Rio Grande do Sul, Porto Alegre, 2011.

MALMGREN, B. et al. Changes in proteins, physical stability and structure in directly heated UHT milk during storage at different temperatures. International Dairy Journal, v. 71 , p. $60-75,2017$. DOI: $10.1016 /$ j. idairyj.2017.03.002

NEWSTEAD, D. F. et al. Plasmin activity in direct-steam-injection UHT-processed reconstituted milk: Effects of preheat treatment. International Dairy Journal, v. 16, n. 6, p. 573-579, 2006. DOI: 10.1016/j. idairyj.2005.11.011

ORNELlAS T. S. et al. Percepção de profissionais de saúde e educação sobre a produção e qualidade do leite destinado ao consumo humano. In: SEMANA ACADÊMICADO CURSO DEAGRONOMIA DO CCAE/UFES, 29., 2018, Alegre. Anais [...]. Alegre: UFES, 2018.

PEREIRA, J. R. et al. Microbiota mesófila 
aeróbia contaminante do leite UHT. Revista do Instituto de Laticínios Cândido Tostes, v. 68, n. 394, p. 25-31, 2013. DOI: $10.5935 / 2238-6416.20130039$

PINTO, C. L. O.; MARTINS, M. L.; VANETTI, M. C. D. qualidade microbiológica de leite cru refrigerado e isolamento de bactérias psicrotróficas proteolíticas. Ciência e Tecnologia de Alimentos, v. 26, n. 3 , p. $645-651,2006$. DOI: $10.1590 / \mathrm{S} 0101-$ 20612006000300025

REZENDE, N. C. M. et al. Ocorrência de microrganismos indicadores em leite UHT ("ultra-high-temperature") integral. Revista Brasileira Ciência Veterinária, v. 7, n. 1, p. 58-60, 2000. DOI: $10.4322 /$ rbcv.2015.178

SANTOS, M. V.; FONSECA, L. F. L. Estratégias para Controle de Mastite e Melhoria da Qualidade de Leite. Pirassununga: Editora Manole, 2007. 314 p.

SERRA, M. J. B. Qualidade microbiana e físico-químico do leite cru produzido na região de Pardinho, SP. Orientador: José Paes de A. Nogueira Pinto. 2004. 37 f. Dissertação (Mestrado em Medicina Veterinária) - Universidade Estadual Paulista, Botucatu, 2004.
SILVA, V. M. A. et al. Avaliação dos Parâmetros de Qualidade de Leites UHT Integral. Caderno de Pesquisa, Ciência e Inovação, v. 2, n. 1, p. 56-66, 2019.

TABIT, F.T. Prevalence and growth characteristics of Bacillus sporothermodurans in UHT milk. British Food Journal, v. 120, n. 10 , p. 2250-2260, 2018. DOI: 10.1108/ BFJ-02-2018-0126.

TRONCO, V. M. Manual para Inspeção da Qualidade do Leite. 4. ed. Santa Maria: UFSM, 2010. 206 p.

WANG, C.; ZHU, Y.; WANG, J. Comparative study on the heat stability of goat milk and cow milk. Indian Journal of Animal Research, v. 50, n. 4, p. 610-613, 2016. DOI: 10.18805/ijar.5961

WESTHOFF, D. Storage study of commercially pasteurized whole milk. Journal of Food Quality, v. 4, n. 3, p. 157-164, 1981. DOI: 10.1111/j.1745-4557.1981.tb00724.x

ZACARCHENCO, P. B. et al. Ocorrência de Bacillus sporothermodurans em leite UAT/ UHT brasileiro e a influência do tratamento térmico. Ciência e Tecnologia de Alimentos, v. 20 , n. 3 , p. $363-368$, 2000. DOI: $10.1590 /$ S0101-20612000000300014 